\title{
Complete Load Analysis of a residential Hall of CUET in Bangladesh and Design of a Roof Top Solar PV System
}

\author{
Md. Shamsul Arifin ${ }^{1}$, M. Tariq Iqbal ${ }^{2}$ \\ ${ }^{1}$ Department of Electrical and Computer Engineering, Memorial University of Newfoundland, St. John's, NL, Canada.
}

\begin{tabular}{l} 
Article Info \\
\hline Article history: \\
Received Jul 11, 2020 \\
Revised Mar 18, 2021 \\
Accepted Mar 22, 2021 \\
\hline Keywords: \\
Roof top solar PV System \\
Load profile \\
Dynamic response \\
Control and protection schemes
\end{tabular}

\section{Corresponding Author:}

\section{Md. Shamsul Arifin}

Department of Electrical and Computer Engineering,

Memorial University of Newfoundland

St. John's, NL, Canada.

Email: msarifin@mun.ca

\begin{abstract}
In this paper a complete load analysis of a residential hall of CUET in Bangladesh is performed, and a roof top solar PV System is designed. At first the load of this building is estimated, and a complete daily load profile is developed. Using the estimated load profile, the size of solar array and other components are estimated. After that, a complete system is designed connecting the components of estimated rating and size. Additionally, an optimization of system is performed using HOMER. Furthermore, the dynamic response of the proposed system is analyzed using Simulink, MATLAB and based on this response essential control and protection schemes are incorporated with the system. The effectiveness of these schemes is also verified by MATLAB simulation.
\end{abstract}

Copyright $\odot 2021$ Institute of Advanced Engineering and Science. All rights reserved.

\section{INTRODUCTION}

With the advancement of modern technology, the demand of energy is increasing day by day. On the contrary, the reserve of fossil fuel which is extensively used to generate electricity is decreasing gradually. As a result, the utilization of renewable resources is becoming popular gradually. Although, hydroelectric generations are the leading energy sources, it is not appropriate for consumers at distribution end. Thereby, the usual renewable sources include solar and wind-based conversion systems. Among the sources the solar PV system is the most popular one [1-4]. The solar PV system utilizes the photon energy to produce electricity. The produced electricity is DC in nature. Thereby some power electronic equipment is required to convert this power to AC and useable to the consumers. Additionally, a storage system is usually installed with the solar PV system. The solar PV is becoming popular and it has several advantages like low transmission and distribution losses, cost effectiveness etc. [5]

Bangladesh is a small country in south Asia region having the area of $147570 \mathrm{Km}^{2}$. It lies between latitudes $20^{\circ}$ and $27^{\circ}$ and longitudes $88^{\circ}$ and $93^{\circ}$ east. It is an over populated country which needs a lot of electricity [5,6]. Currently Bangladesh has $20000 \mathrm{MW}$ of installed capacity of electricity generation. In 2015, $80 \%$ of people were under the advantages of electricity. In 2018 the coverage has increased to 95\%. [7]

Bangladesh needs $34000 \mathrm{MW}$ of electricity to produce desired economic growth. Although most of the people are getting advantages of electricity directly or indirectly, the per capita consumption of electricity is very low in Bangladesh. Presently, the power sector of Bangladesh is mainly dependent on natural gas resources to meet the demand. However, it also has hydroelectric power plant at Kaptai, Chittagong and several coal based power plants [7-9]. Figure 1 represents the fuel sharing scenario for electricity generation in Bangladesh. From the figure it is observed that the country has $9843 \mathrm{MW}$ of natural gas based generation which is approximately $53.8 \%$ of total generation [10]. The total installed capacity of Bangladesh is about 20000 MW, which also includes the renewable resources [7]. 


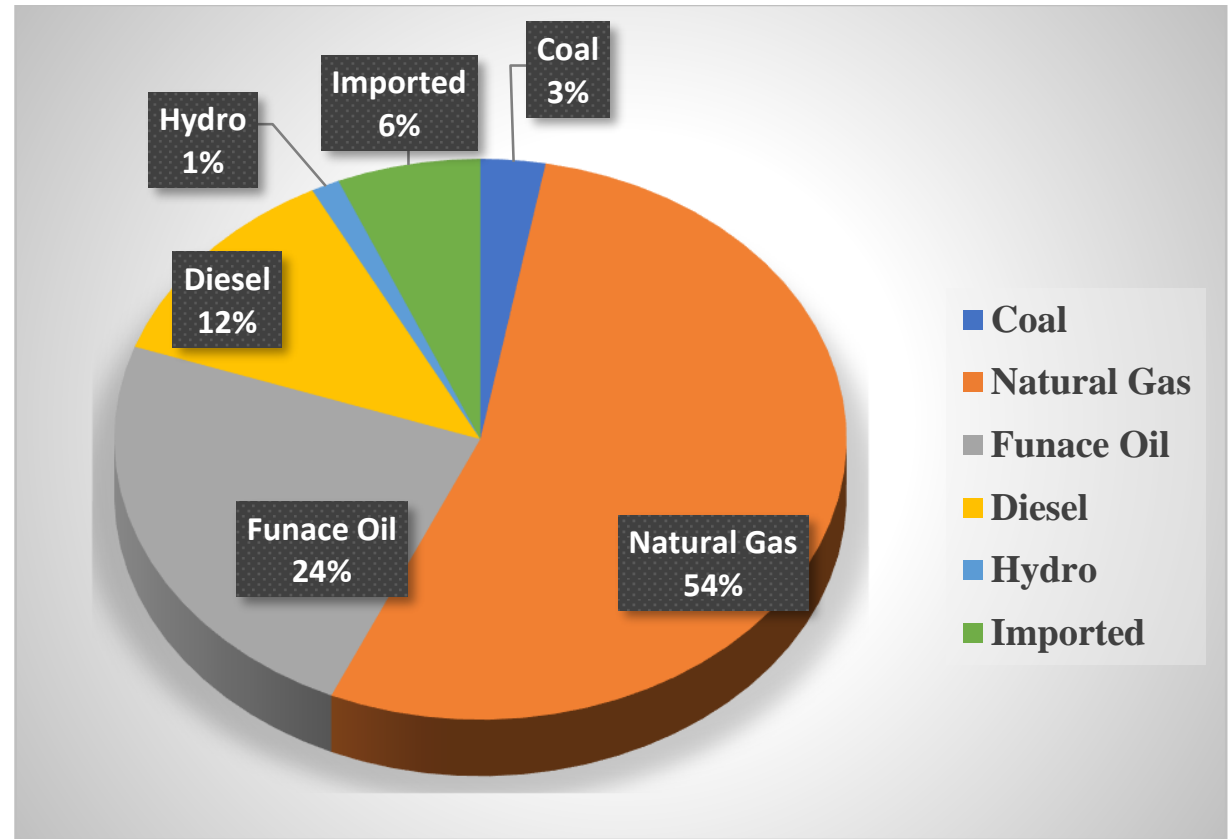

Figure 1. Fuel sharing scenario for electricity generation in Bangladesh [10].

Bangladesh although having adequate solar resources, the utilization of renewable energy is not sufficient. However, many projects and initiatives are taken to utilize solar energy recently in Bangladesh. Currently Bangladesh has about $17 \mathrm{MW}$ of total solar and wind power generation. The weather condition of Bangladesh is very suitable for producing solar PV energy. This country has the weather condition to generate $20 \mathrm{GW}$ of renewable energy [7]. At present, Bangladesh has $15 \mathrm{MW}$ of distributed solar energy capacity which are being utilized to support rural household loads. The government of Bangladesh has already taken steps to set up nineteen grid connected solar power plant; those can contribute up to 1070MW in near future [7]. The government organization Bangladesh Power Development Board (BPDB) and other national and foreign NonGovernment Organizations (NGO) are working together in various project regarding to renewable energy [6,7,11-14].

In Bangladesh usually two types of solar systems are used. They are solar home system (SHS) and solar microgrid system. A solar home system (SHS) is a small power supply unit which is appropriate for the residential load. Usually the solar home system includes solar panel, a small storage and a power conditioning unit. Solar home systems are useful for remote areas where grids are not available. However, it is not applicable for support medium or high load and the systems are not usually interconnected. On the other hand, solar microgrid is a small and integrated arrangement for converting solar energy to electricity. There many panels are interconnected as well as some controller and monitoring devices are embedded in the system. The loads of the microgrid may be distributed or lumped at a point $[6,7,10,11]$.

Significant researches have been done based on renewable energy sector of the whole world as well as Bangladesh. However, the researches can be categorized into two main streams. One group of the researchers focus on the study of present scenario of renewable energy. They mainly discuss about the potentials and viabilities of renewable energy, status, government plan, market of renewable sources etc. The researchers in this stream usually present statistical data and analysis in their papers [5, 6,8,9,13-21]. However other group focus on designing renewable energy based systems and structure considering various technical specifications, limitations and other conditions [1-4,22-31].

In this paper, a total load analysis will be performed for Shahid Mohammad Shah Hall, a residential hall of CUET in Bangladesh. At first the load analysis will be performed, and a complete load profile will be developed based on the energy consumption data. Furthermore, the feasibility of a roof top solar PV system will be analyzed. After that, optimization of system will be performed using HOMER. Moreover, a dynamic simulation model will be built and required control and protection schemes will be designed for this model.

The paper is organized as follows. In section II the solar availability and load estimation for the proposed site is performed. The design, sizing and optimization of the roof top solar system is described in section III. The dynamic simulation and design of control \& protection scheme is presented in section IV. At last a conclusion is drawn in section V. 


\section{THE SOLAR AVAILABILITY AND LOAD ESTIMATION FOR THE PROPOSED SITE}

\subsection{Solar radiation and Temperature Condition}

Chittagong is situated at $22.3^{0}$ latitude and $91.8^{0}$ longitude. and the main port city of Bangladesh. This place has a great potential to generate solar energy as it has $120 \mathrm{Km}$ of coastal beach. The average temperature profile of Chittagong is presented in Figure 2. Furthermore, the monthly radiation profile is presented in Figure 3. From these profiles it is observed that there is a very good scope to produce solar electricity throughout the year. However, from February to May the temperature is relatively higher, and it is considered as summer season. The average daily solar radiation is found $4.71 \mathrm{Kwh} / \mathrm{m} 2 /$ day.

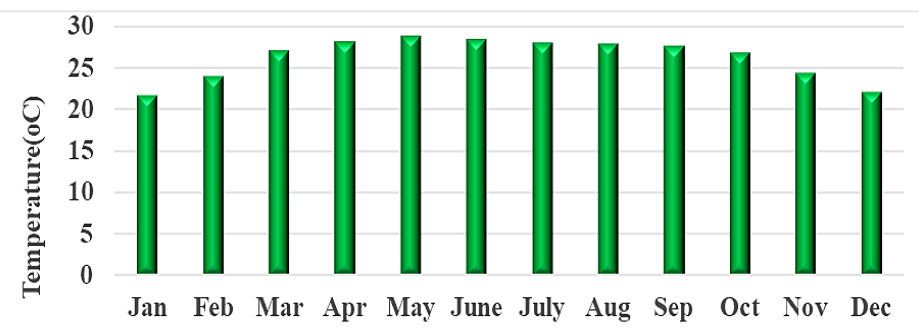

Figure 2. Monthly Temperature profile of Chittagong.

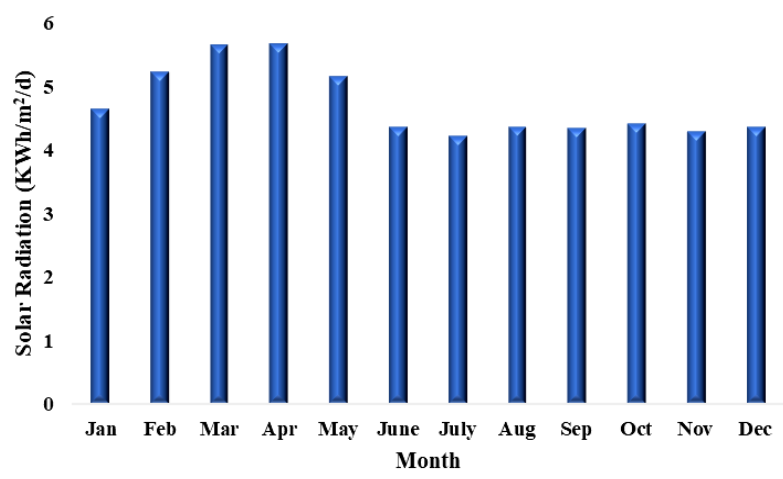

Figure 3. Monthly radiation profile of Chittagong.

\subsection{Information and Load Estimation of the Proposed Site}

Shahid Mohammad Shah Hall is one of the residential halls where approximately 400 students live. This building is a " $Z$ " shaped building have a lot of potential for solar energy. Figures 4 and 5 show the location and the dimension of this hall, respectively. The total space available in roof top is calculated as $1319.15 \mathrm{~m}^{2}$. Figure 6 represents the annual load profile of the selected building at CUET. Furthermore, Figure 7 represents an average hourly load profile of the selected hall. Considering the load profile, the average load is found $25.475 \mathrm{KW}$.

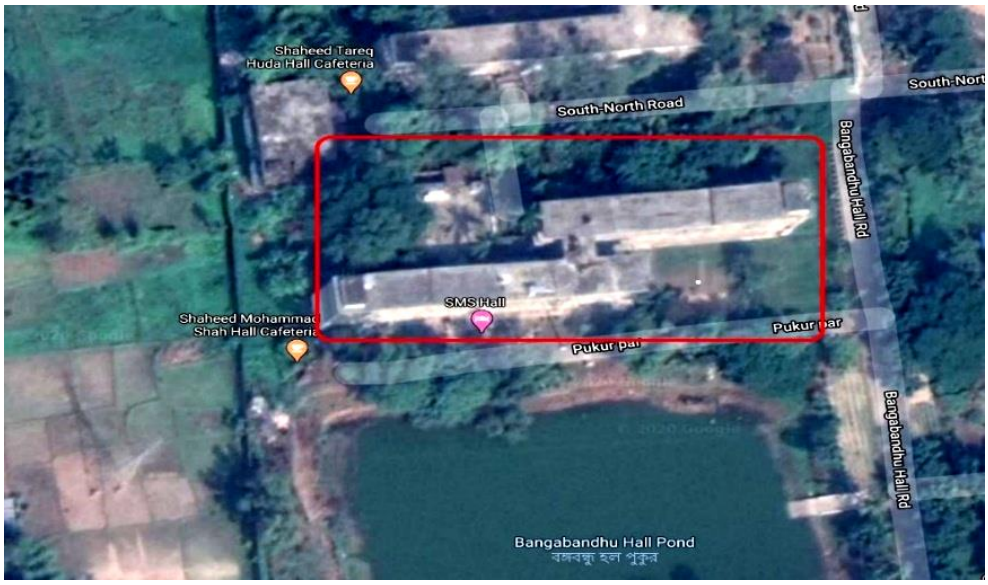


Figure 4. The Location of Shaheed Mohammad Shah Hall, CUET. [32]

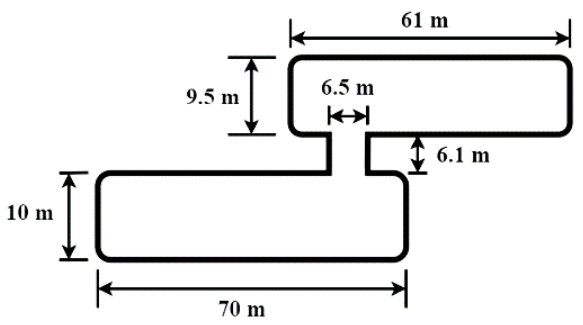

Figure 5. The dimension of Shaheed Mohammad Shah Hall, CUET.

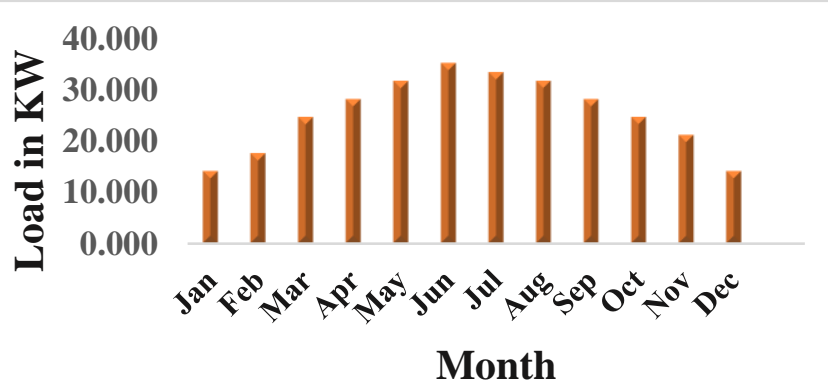

Figure 6. The annual load profile and solar radiation profile of CUET.

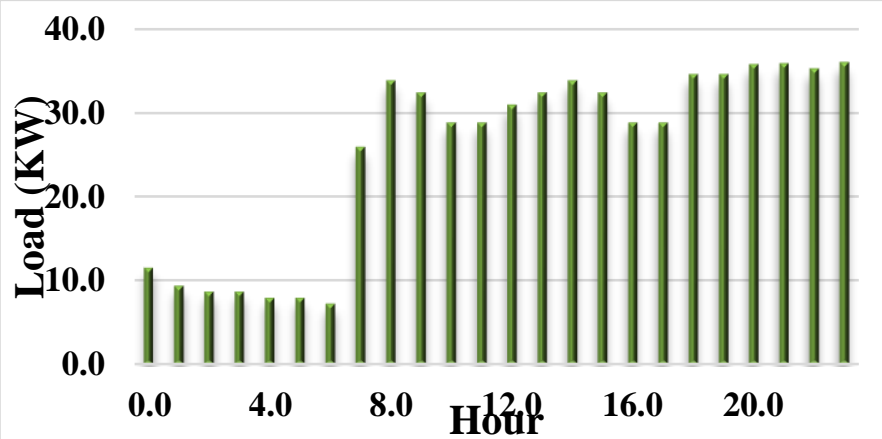

Figure 7. The hourly load profile of Shaheed Mohammad Shah Hall, CUET.

\section{THE DESIGN, SIZING AND OPTIMIZATION OF THE PROPOSED SYSTEM}

\subsection{Design and Sizing of the Proposed System}

For this system, considering the availability and cost $300 \mathrm{~W} 30 \mathrm{~V}$ solar panel is selected. For the storage system $12 \mathrm{~V} 100$ Ah batteries are selected. Table 1 shows the detail calculations and estimation of the amount of required solar panels. Furthermore, Table 2 presents the estimation of no. of required batteries. The DC bus voltage is selected at $360 \mathrm{~V}$ considering the load, panel voltage and battery voltages.

Table 1. The estimation of the amount of required solar panels

\begin{tabular}{ll}
\hline Daily load: & $25.475 \mathrm{KW}$ \\
Daily Consumed Energy: & $611.4 \mathrm{KWh}$ \\
Monthly Consumed Energy: & $18342 \mathrm{KWh}$ \\
Average solar radiation: & $4.71 \mathrm{KWh} / \mathrm{m} 2 /$ day \\
Size of over all system ( Daily Consumed Energy/ Average & $129.8 \approx 130 \mathrm{KW}$ \\
solar radiation): & $0.3 \mathrm{KW}$ \\
Rated power of one panel: & 0.77 \\
\hline
\end{tabular}




\begin{tabular}{ll}
\hline $\begin{array}{l}\text { Total no. of panel required (Size of over all system/(Rated } \\
\text { power of one panel * Derate factor)): }\end{array}$ & $562.77 \approx 563$ \\
Total panel Space required: & $1095 \mathrm{~m}^{2}$
\end{tabular}

Table 2 . The estimation of the no. of required batteries
Energy required at night:
$\begin{gathered}\text { Total No. of battery required (required Ah/rated } \\ \text { Ah): }\end{gathered}$

From the calculation we can conclude that the roof top has enough space to accommodate these number of panels as its total space is $1319.15 \mathrm{~m}^{2}$. For the selected bus voltage, total no of solar panel required to be connected in series is 12 and the no. of parallel string required is 47 . Consequently, the total system incorporates 564 no. of solar panels, which is approximately same of total no. of required panel. Similarly, for storage system 9 strings of batteries are required where, each string contains 30 batteries. As a result, the total system has 270 no. of batteries, which is the closest approximation of the total no. of required batteries. Furthermore, considering approximately $20 \%$ more than the rated system size, two inverters of $80 \mathrm{KW}$ rating are selected for the system. The solar strings are divided into two halves and connected to each inverter. Consequently, one inverter incorporates 24 no. of parallel solar strings and other one has 23 strings. Similarly, for batteries one inverter has 5 parallel strings of batteries and another has 4 strings. Figure 8 shows the details connection layout of a subsystem which includes one inverter. The total single line diagram of the system is presented in Figure 9.

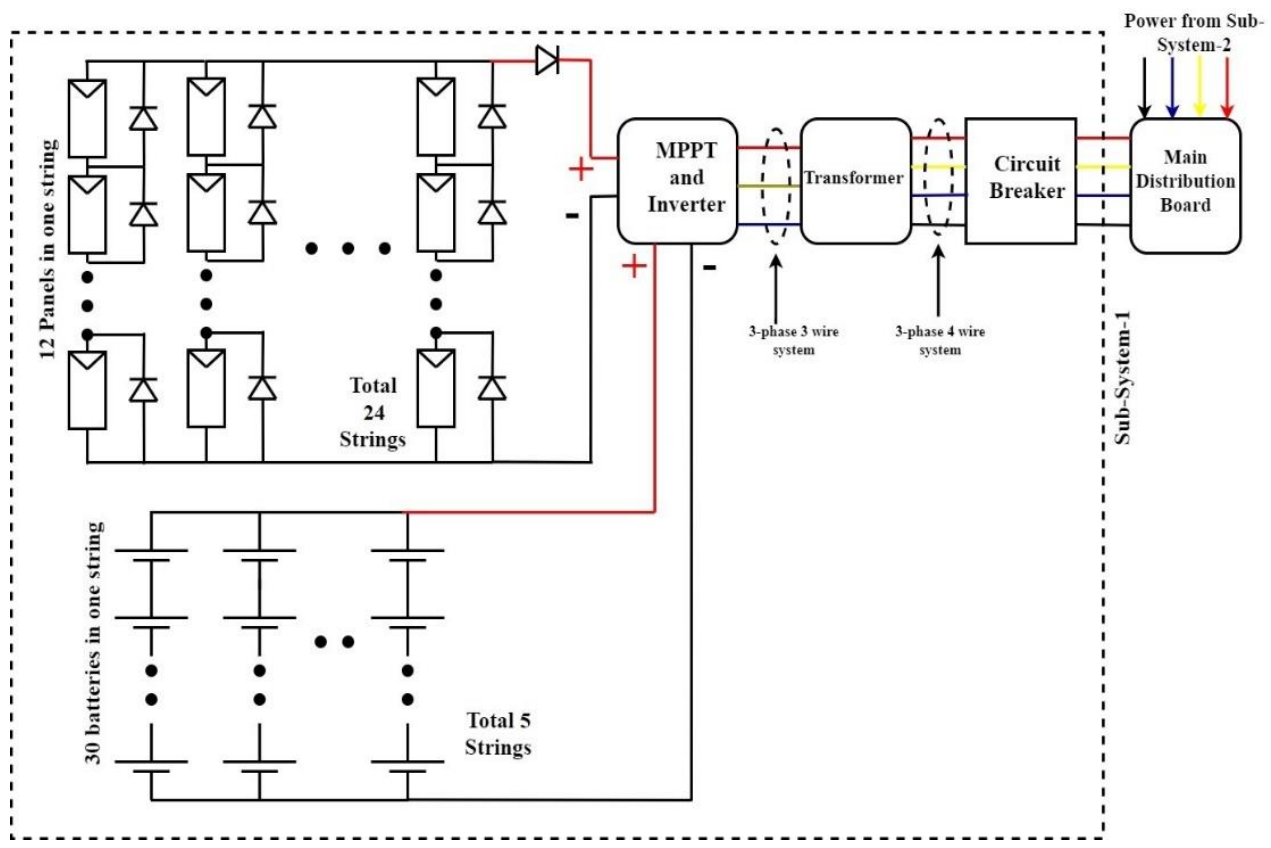

Figure 8. Detail connection diagram of the proposed system. 


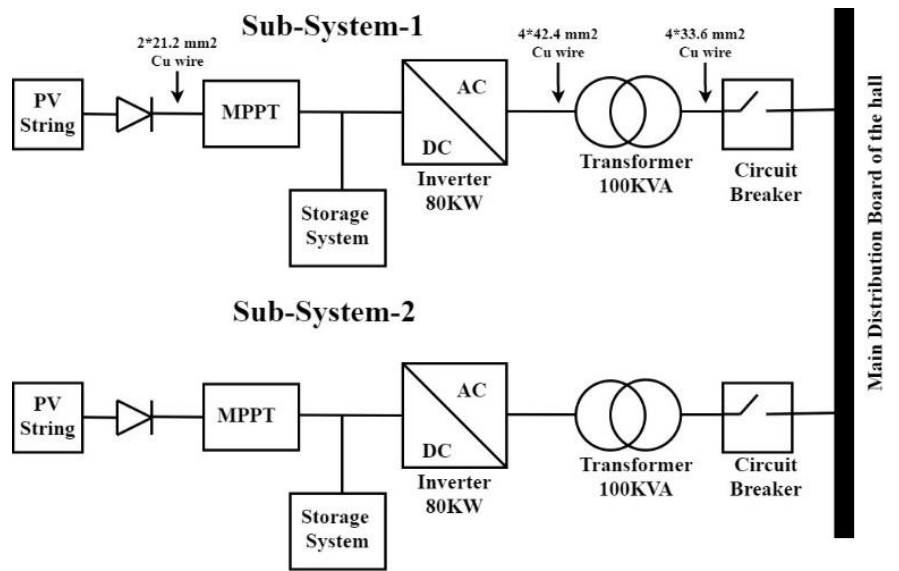

Figure 9. Single line connection diagram of the proposed system.

\subsection{Optimization of the Proposed System Using Homer}

The proposed system is also analyzed using homer software. The optimum generation and size of each components are achieved from the analysis using HOMER. Figure 10 shows the proposed system construction in HOMER software. The optimized result of the system suggested by HOMER is illustrated in Figure 11. Additionally, the electrical energy details of the proposed system is presented in Figure 12. It is observed that, the optimized system suggested by homer also contains very few extra energies. So, we can conclude our system can support the load effectively.

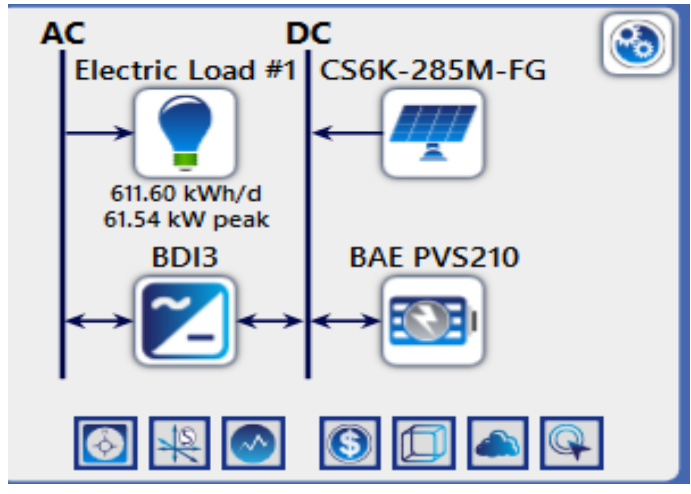

Figure 10. Construction of the proposed system in HOMER

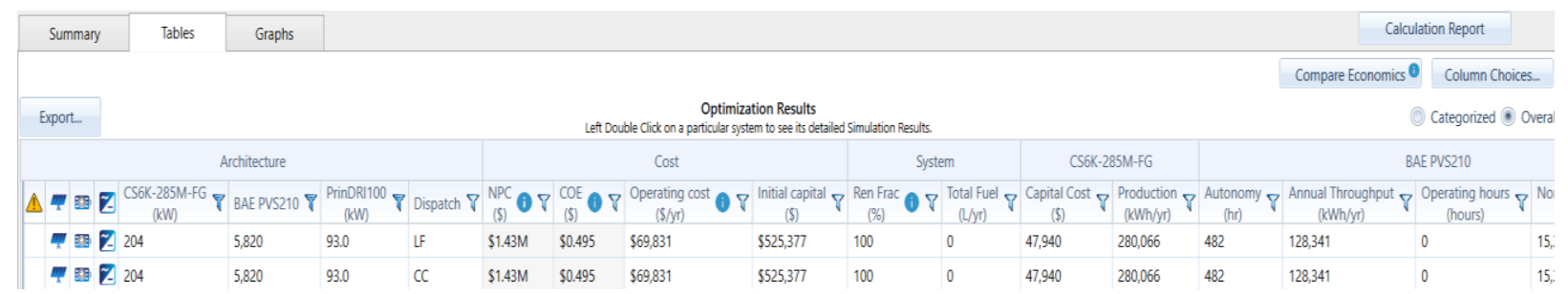

Figure 11. Optimized results obtained from HOMER. 


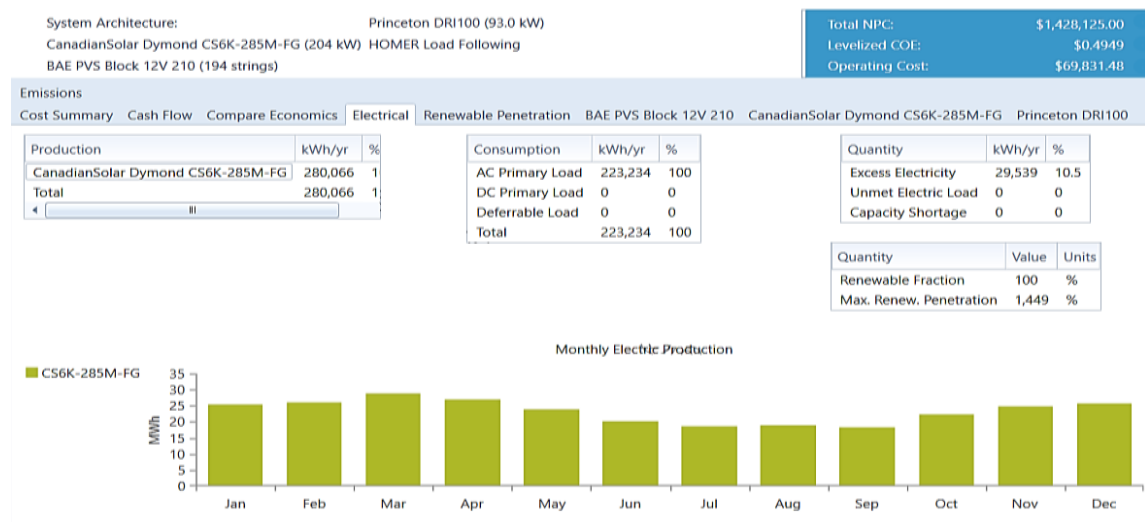

Figure 12. The electrical quantities details obtained from HOMER.

\section{DYNAMIC SIMULATION AND DESIGN OF CONTROL \& PROTECTION SCHEMES}

\subsection{Dynamic Simulation and Analysis}

The proposed system is simulated in MATLAB R2017a. Figure 13 shows the model for simulation. Here the output of solar panels is connected to the MPPT (Maximum Power Point Tracking) converter. For this simulation Fractional Open Circuit Voltage MPPT Method is used [32-34]. A standard 360V bus is selected for connecting battery. The output of $360 \mathrm{~V}$ bus is given to a DC-AC inverter. IGBTs are selected for switching purposes at a frequency of $20 \mathrm{KHz}$. Figures 14 to 16 represent the voltage at MPPT output, the load voltage, the load power.

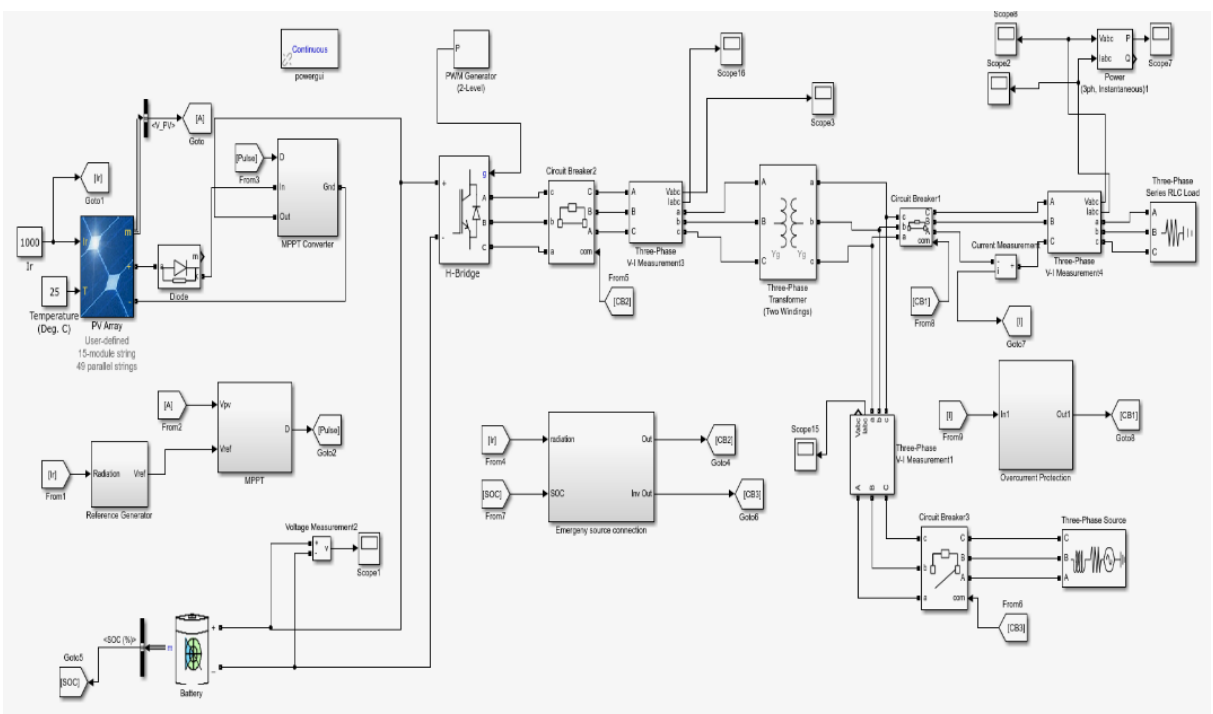

Figure 13. The complete Simulink model of the proposed system. 


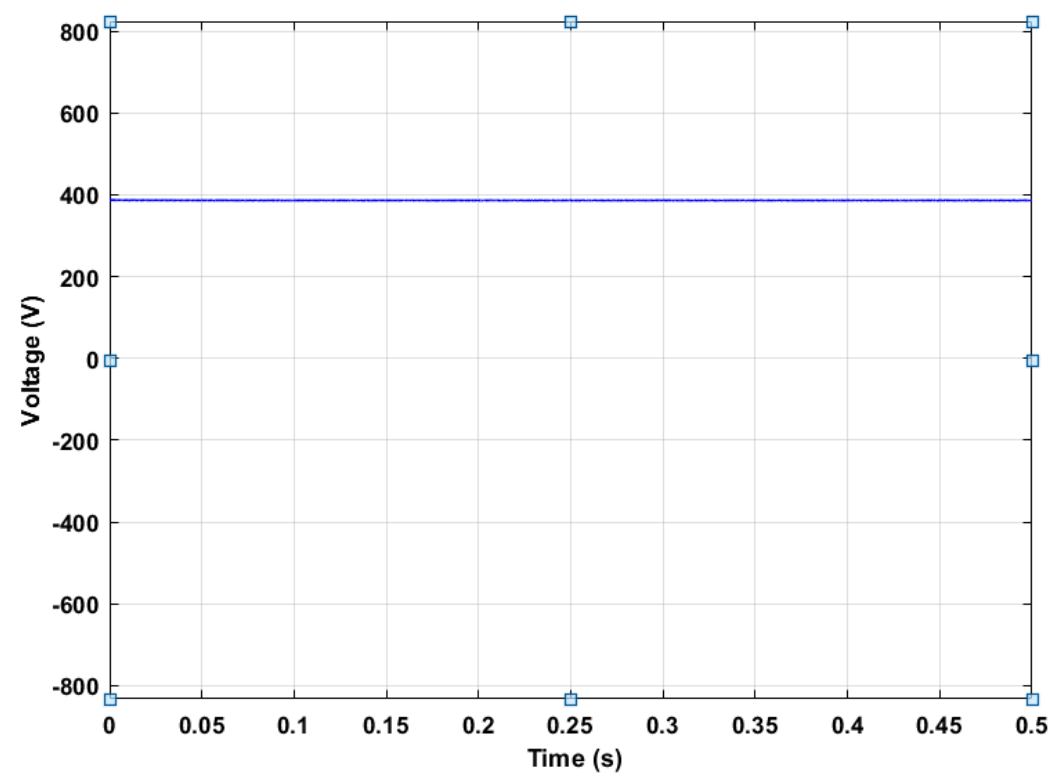

Figure 14. The Voltage at MPPT Output.

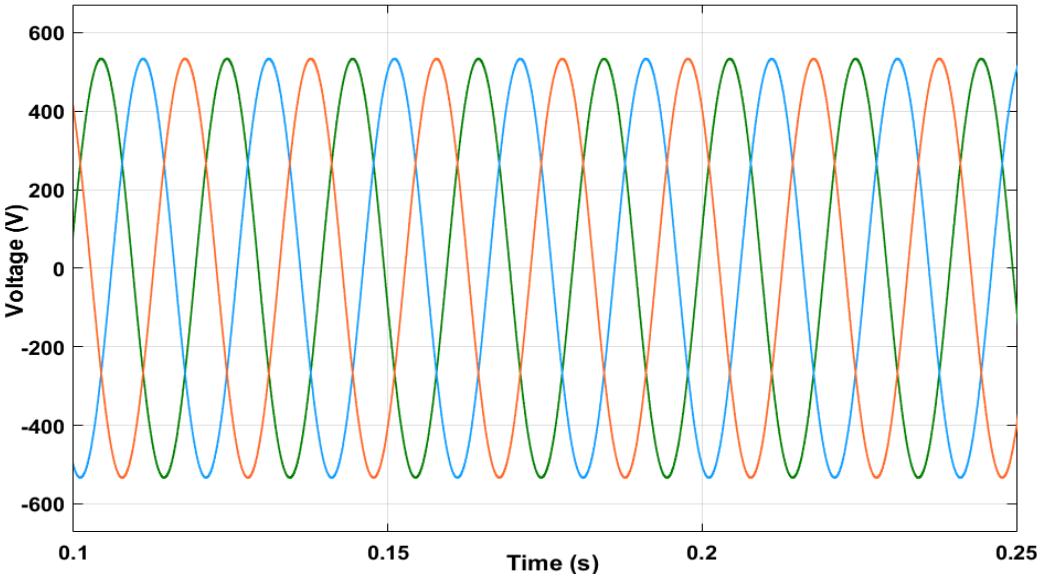

Figure 15. The Load Voltage.

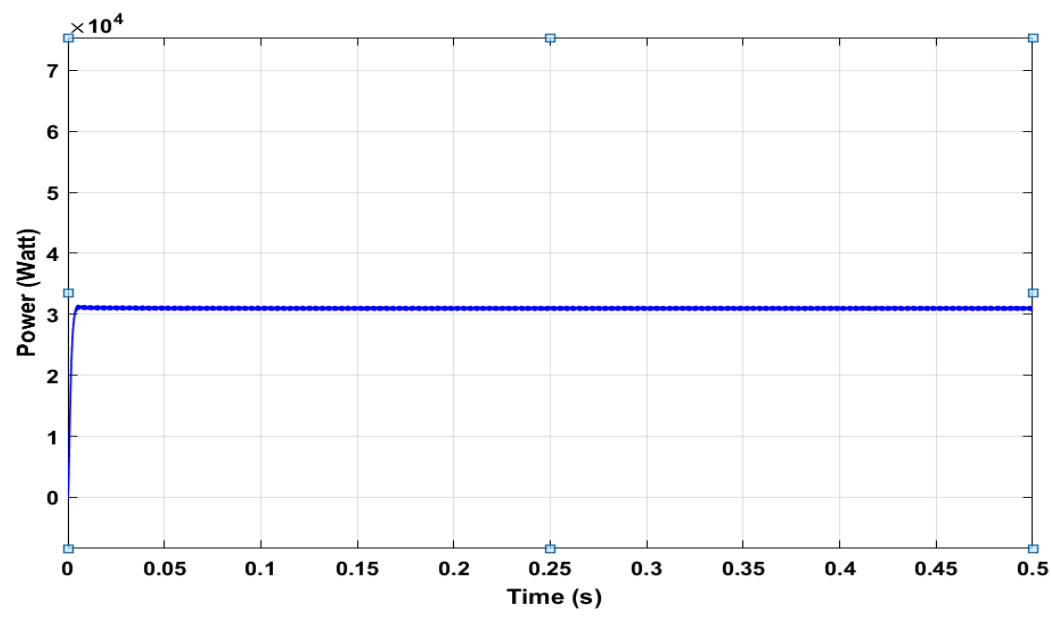

Figure 16. The Load Power.

\subsection{Design of Control and Protection Scheme}




\subsubsection{MPPT Control Scheme}

The output of solar panels is connected to the MPPT (Maximum Power Point Tracking) converter. For this simulation Fractional Open Circuit Voltage MPPT Method is used [33]-[35]. According to this algorithm the MPPT voltage is assumed to be a linear fraction of open circuit voltage. A close loop control system is designed to maintain the output at desired level. Figure 17 shows the MPPT voltage of the string which is achieved from the output of the MPPT converter.

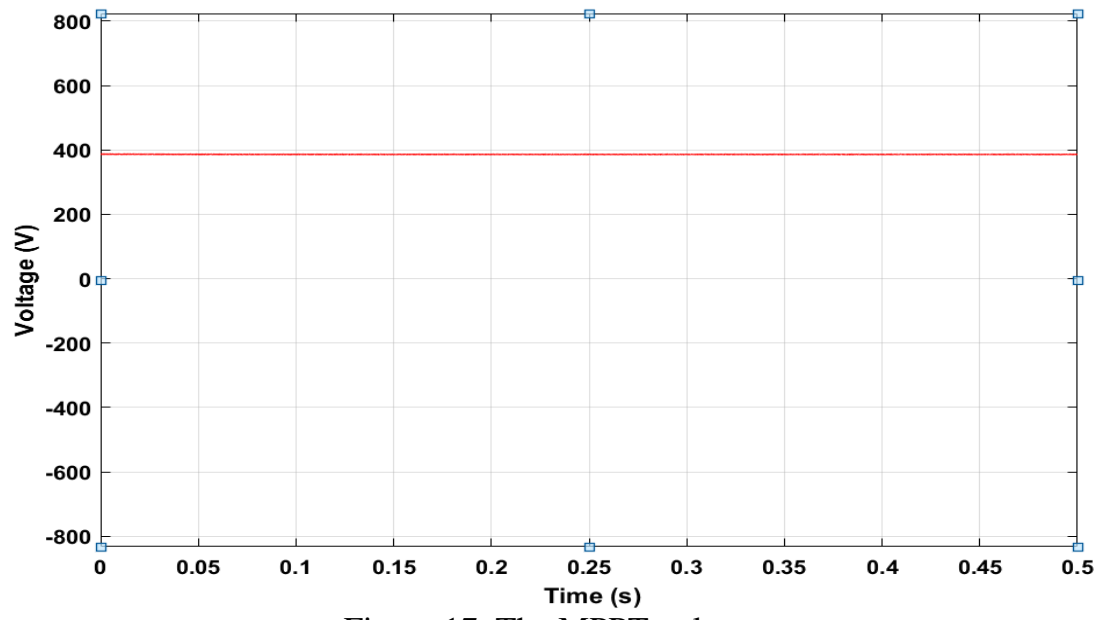

Figure 17. The MPPT voltage.

\subsubsection{Overcurrent Protection}

A circuit breaker1 (CB1) is used to provide protection against overcurrent. Figure 18 represents the overcurrent protection scheme used in the system. Figure 19 shows the functionality of this scheme after introducing a three-phase fault at $0.2 \mathrm{~s}$.

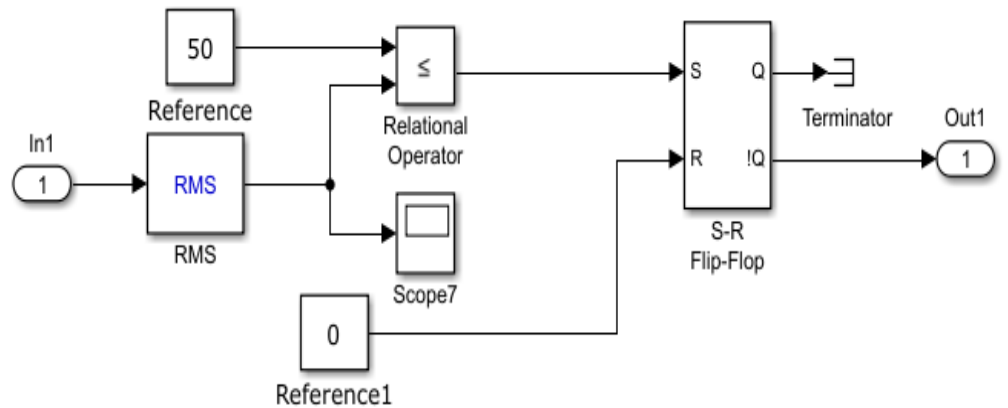

Figure 18. The overcurrent protection scheme.

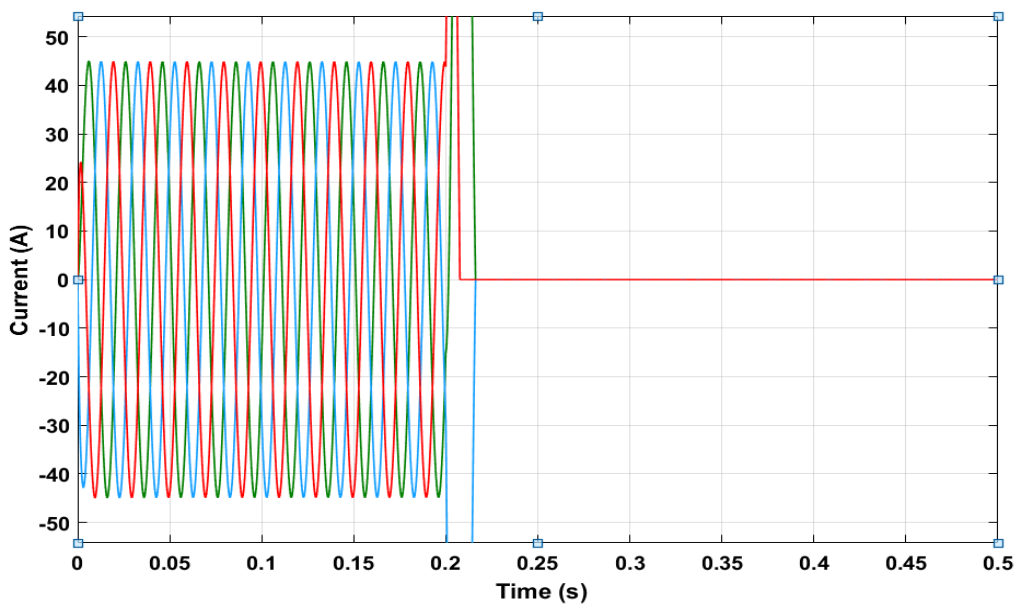

Figure 19. The Load current waveform after introducing fault at $\mathrm{T}=0.2 \mathrm{~s}$.

\subsubsection{Emergency Source Connection}

IJEEI, Vol.9, No. 1, March 2021: 198 - 209 
If at night, the battery charge level will be gone below $50 \%$ then an emergency source is automatically connected using circuit breaker3 (CB3) to avoid blackout. At this time, the CB2 will be automatically disconnected. The emergency source can be an embedded generator or grid. Figure 20 shows the emergency source connection scheme for the system. However, the waveform of grid current for such condition is presented in Figure 21.

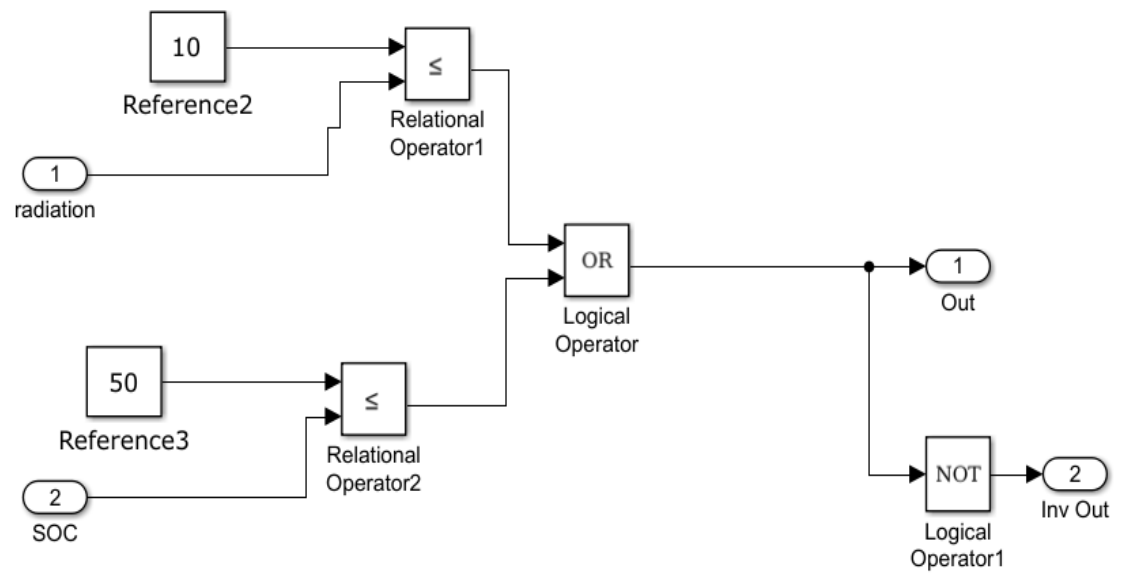

Figure 20. Emergency source connection scheme.

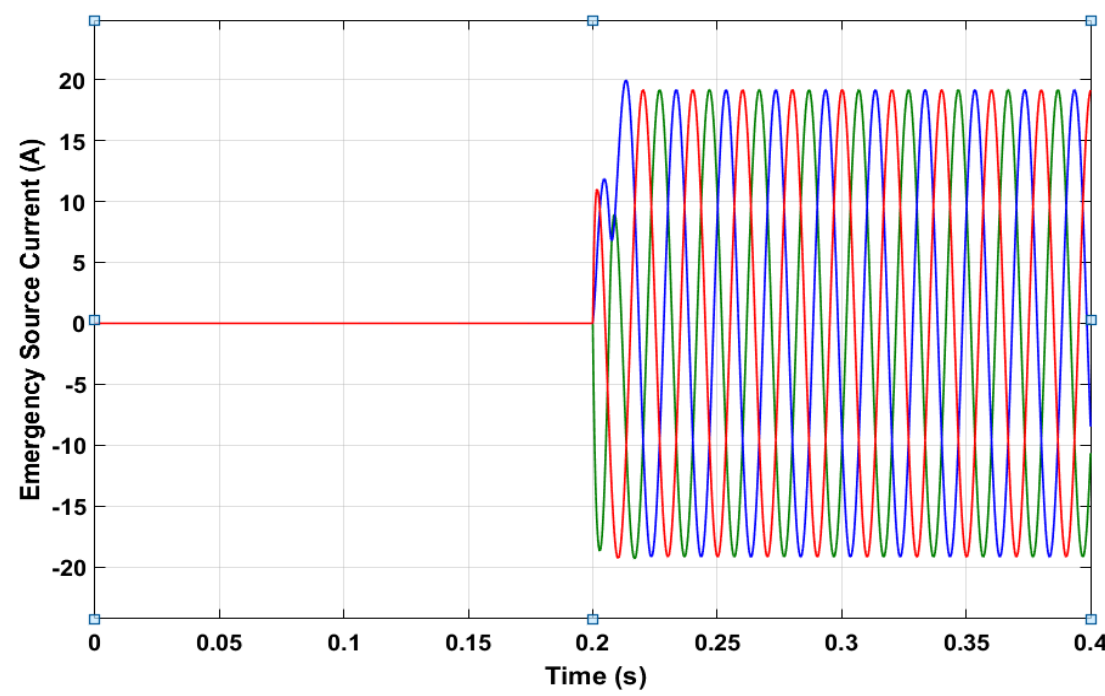

Figure 21. The waveform of source current, which shows that the emergency source is connected at $\mathrm{T}=0.2 \mathrm{~s}$.

\subsubsection{The grounding System}

The total system requires proper grounding system to be protected against any faulty situation. There are two types of grounding like DC and AC grounding is provided and both types of grounding wires are interconnected with each other. This type of grounding system is single point grounding, which meets the requirement of National Electrical Code (NEC). Without grounding system, the system may be damaged at the time of lighting or other faulty situations. Figure 22 shows the overall grounding system, which is indicated by green wires. 


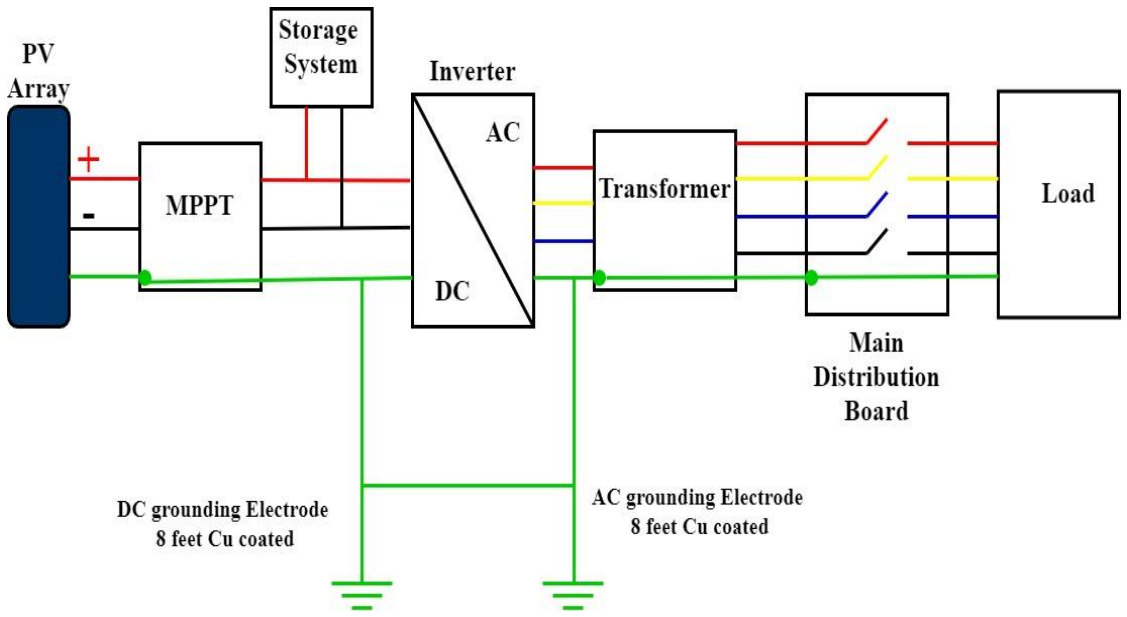

Figure 22. The grounding system layout.

\section{CONCLUSION}

A Complete Load Analysis of Shahid Mohammad Shah Hall, a residential hall of CUET in Bangladesh is performed in this project. After that, a Roof Top PV System is designed. At first the load is calculated, and the daily load profile is developed. Then the feasibility of the roof top solar panel system is analyzed using HOMER. After that, the total system is designed in Simulink, MATLAB to observe the dynamic response of the proposed system. The dynamic response of such system is found quite satisfactory. Different types of control and protection scheme is developed to make the system robust against any abnormal or changing situations. Form this study we can say that this system is completely feasible. The future works may include:

- This proposed system is an isolated system with having solar PV and battery storage. However, it produces some extra energy. For this reason, to design and analysis of a grid connected net metering system for such a building is a good future work.

- Some analysis can be performed using some other renewable resources like wind-based generation.

- The feasibility of roof top solar panel can be studied for academic and administrative buildings of CUET.

- The size of the proposed system depends on several issues. So, dependency of the sizing on different factors can be studied both theoretically and analytically.

\section{REFERENCES}

[1] S. Datto, M. H. O. Roshid, and M. M. Rahman, "Design of a Cost Effective and environment friendly Off-Grid Wind-Diesel Hybrid Power System in Kutubdia Island of Bangladesh,” Int. J. Adv. Res. Comput. Eng. Technol. IJARCET, vol. 2, no. 2, 2013.

[2] R. M. Nahid-Al-Masood et al., "Design of a Cost Effective Off-Grid Wind-Diesel Hybrid Power System in an Island of Bangladesh,” World Acad. Sci. Eng. Technol., vol. 60, pp. 312-315, 2011.

[3] S. Salehin, M. M. Ehsan, S. Noor, and A. K. M. Sadrul Islam, "Modeling of an optimized hybrid energy system for Kutubdia Island, Bangladesh," in Applied Mechanics and Materials, 2016, vol. 819, pp. 518-522.

[4] R. A. Thokar, N. Gupta, K. R. Niazi, A. Swarnkar, S. Sharma, and N. K. Meena, "Optimal Integration and Management of Solar Generation and Battery Storage System in Distribution Systems under Uncertain Environment," Int. J. Renew. Energy Res. IJRER, vol. 10, no. 1, pp. 11-12, Mar. 2020.

[5] Md. Alam Hossain Mondal and A. K. M. Sadrul Islam, "Potential and viability of grid-connected solar PV system in Bangladesh," Renew. Energy, vol. 36, no. 6, pp. 1869-1874, Jun. 2011.

[6] A. H. Bagdadee and A.-A.-M. Fakruddin, “ASSESSMENT OF PV OPERATION IN BANGLADESH," Int. $J$. Eng. Adv. Technol. Stud., vol. 2, no. 4, p. 16, 2014.

[7] "Electricity sector in Bangladesh," Wikipedia. Jun. 03, 2020, Accessed: Jun. 03, 2020. [Online]. Available: https://en.wikipedia.org/w/index.php?title=Electricity_sector_in_Bangladesh\&oldid=960479138

[8] S. K. Nandi and H. R. Ghosh, "Prospect of wind-PV-battery hybrid power system as an alternative to grid extension in Bangladesh," Energy, vol. 35, no. 7, pp. 3040-3047, Jul. 2010.

[9] S. K. Nandi and H. R. Ghosh, "A wind-PV-battery hybrid power system at Sitakunda in Bangladesh," Energy Policy, vol. 37, no. 9, pp. 3659-3664, Sep. 2009.

[10] "Bangladesh Power Development Board." https://www.bpdb.gov.bd/ (accessed Jun. 03, 2020).

[11] "Infrastructure Development Company Limited (IDCOL)." https://www.idcol.org/ (accessed Jun. 03, 2020).

[12] "Bangladesh to complete 7.4 MW of solar capacity in April," pv magazine International. https://www.pvmagazine.com/2019/03/20/bangladesh-to-complete-7-4-mw-of-solar-capacity-in-april/ (accessed Jun. 03, 2020). 
[13] S. I. Khan, M. U. Mahfuz, T. Aziz, and N. M. Zobair, "Prospect of hybrid wind system in Bangladesh," Second International Conference on Electrical and Computer Engineering, pp. 212-215, 2002.

[14] M. H. Masud, M. Nuruzzaman, R. Ahamed, A. A. Ananno, and A. N. M. A. Tomal, "Renewable energy in Bangladesh: current situation and future prospect," Int. J. Sustain. Energy, vol. 39, no. 2, pp. 132-175, Feb. 2020.

[15] Md. A. Hossain Mondal, "Economic viability of solar home systems: Case study of Bangladesh," Renew. Energy, vol. 35, no. 6, pp. 1125-1129, Jun. 2010.

[16] M. S. Islam, R. Akhter, and M. A. Rahman, "A thorough investigation on hybrid application of biomass gasifier and PV resources to meet energy needs for a northern rural off-grid region of Bangladesh: A potential solution to replicate in rural off-grid areas or not?," Energy, vol. 145, pp. 338-355, Feb. 2018.

[17] A. K. M. S. Islam, M. Islam, and T. Rahman, "Effective renewable energy activities in Bangladesh," Renew. Energy, vol. 31, no. 5, pp. 677-688, Apr. 2006.

[18] Md. H. Kabir, W. Endlicher, and J. Jägermeyr, "Calculation of bright roof-tops for solar PV applications in Dhaka Megacity, Bangladesh,” Renew. Energy, vol. 35, no. 8, pp. 1760-1764, Aug. 2010.

[19] C.-C. Kung and J. E. Mu, "Prospect of China's renewable energy development from pyrolysis and biochar applications under climate change," Renew. Sustain. Energy Rev., vol. 114, p. 109343, Oct. 2019.

[20] A. B. Karim, S. S. Avro, and S. Shahriar, "PROSPECT OF GEOTHERMAL ENERGY RESOURCES IN BANGLADESH," Int. J. Renew. Energy Resour., vol. 8, pp. 22-28, 2018.

[21] C. R. Kumar. J and M. A. Majid, "Renewable energy for sustainable development in India: current status, future prospects, challenges, employment, and investment opportunities," Energy Sustain. Soc., vol. 10, no. 1, p. 2, Jan. 2020.

[22] A. H. Mondal and M. Denich, "Hybrid systems for decentralized power generation in Bangladesh," Energy Sustain. Dev., vol. 14, no. 1, pp. 48-55, Mar. 2010.

[23] S. Bahramara, M. P. Moghaddam, and M. R. Haghifam, "Optimal planning of hybrid renewable energy systems using HOMER: A review,” Renew. Sustain. Energy Rev., vol. 62, pp. 609-620, Sep. 2016.

[24] M. Nurunnabi and N. K. Roy, "Grid connected hybrid power system design using HOMER - 2015 International Conference on Advances in Electrical Engineering (ICAEE), pp. 18-21, Dhaka, 2015.

[25] Md. M. Roni, I. U. Hoque, and T. Ahmed, "Comparative Study of Levelized Cost of Electricity (LCOE) for Concentrating Solar Power (CSP) and Photovoltaic (PV) Plant in the Southeastern Region of Bangladesh," International Conference on Electrical, Computer and Communication Engineering (ECCE), pp. 1-6, Feb. 2019.

[26] M. S. H. Lipu, G. Hafiz, S. Ullah, A. Hossain, and Y. Munia, "Design Optimization and Sensitivity Analysis of Hybrid Renewable Energy Systems: A case of Saint Martin Island in Bangladesh," Int. J. Renew. ENERGY Res., vol. 7, no. 2, pp. 988-998, 2017.

[27] L. Benaaouinate, M. Khafallah, D. Voyer, A. Mesbahi, and T. Bouragba, "Nonlinear Control Based on Fuzzy Logic for a Wind Energy Conversion System Connected to the Grid," Int. J. Renew. Energy Res. IJRER, vol. 10, no. 1, pp. 193-204, Mar. 2020.

[28] J. Zhang and Y. Xuan, "An integrated design of the photovoltaic-thermoelectric hybrid system," Sol. Energy, vol. 177, pp. 293-298, Jan. 2019.

[29] M. Alam and S. Bhattacharyya, "Decentralized renewable hybrid mini-grids for sustainable electrification of the off-grid coastal areas of Bangladesh," Energies, vol. 9, no. 4, p. 268, 2016.

[30] M. M. S. Khan, M. S. Arifin, A. Haque, and Nahid-Al-Masood, "Stability Analysis of Power System with the Penetration of Photovoltaic Based Generation," Int. J. Energy Power Eng., vol. 2, no. 2, pp. 84-89, Jan. 2014.

[31] Md. S. Arifin, M. M. S. Khan, A. Haque, and Nahid-Al-Masood, "Improvement of load-margin and bus voltage of Bangladesh power system with the penetration of PV based generation," 2013 International Conference on Informatics, Electronics and Vision (ICIEV), pp. 1-5, May 2013.

[32] "Google Maps," Google Maps. https://www.google.com/maps/place/Chittagong+University+of+Engineering+and+Technology+(CUET)/@22. 4614888,91.9693197,173m/data=!3m1!1e3!4m5!3m4!1s0x30ad2fca34ae5549:0x35c88a37b3e90e97!8m2!3d2 $2.4619433 ! 4 d 91.9710592$ (accessed Jun. 11, 2020).

[33] D. Baimel, S. Tapuchi, Y. Levron, and J. Beliko, "Improved Fractional Open Circuit Voltage MPPT Methods for PV Systems," Electronics, vol. 8, no. 3, 2019,

[34] K. R. Bharath and E. Suresh, "Design and implementation of improved fractional open circuit voltage based maximum power point tracking algorithm for photovoltaic applications," Int. J. Renew. Energy Res. IJRER, vol. 7, no. 3, pp. 1108-1113, 2017.

[35] M. J. S. Kumari, C. S. Babu, and M. T. R. Kullayappa, "Design and analysis of open circuit voltage based maximum power point tracking for photovoltaic system," Int. J. Adv. Sci. Technol., vol. 2, no. 2, pp. 51-86, 2011. 